\title{
IMPARCIALIDADE JUDICIAL À BRASILEIRA?
}

\section{BRAZILIAN JUDICIAL IMPARTIALITY?}

Alexandre Douglas Zaidan de Carvalho*

\section{RESUMO}

No Brasil, a formação da autoimagem da magistratura tem sido em grande parte constituída em torno do grau de autonomia do Judiciário, articulada como reação à interferência dos demais poderes. Tais reações estão presentes inclusive quando o recurso à independência dos juízes sirva a usos políticos que conspirem contra a efetiva autonomia do direito. Visto como órgão da estrutura de poder aliado à "governabilidade" na cúpula, e gestor burocrático de demandas de massa na base, a independência de juízes e tribunais pouco tem representado para a afirmação do sentido de liberdade. $O$ déficit de transparência, as interferências governamentais e a organização corporativa da magistratura potencializam o risco da conversão do Judiciário em instrumento aristocrático da proteção de redes organizadas por elites políticas e econômicas interessadas na ampliação de seus privilégios. Por sua vez, a estabilização do alto grau de exclusão, refletido na autocompreensão das instituições judiciais, contribui para a percepção de um Judiciário que se adapta defensivamente às demandas dos grupos de pressão. Isso não implica, porém, afirmar a descrição caricatural de uma imparcialidade à brasileira. Tal perspectiva não descarta, antes reforça, o interesse numa descrição adequadamente complexa da administração de justiça no discurso constitucional.

\section{ABSTRACT}

The formation of the self-image of the judiciary has been largely constituted around the degree of autonomy of the Judiciary in Brazil. In spite of judicial independence has been articulated as a reaction to the interference of the other power spheres, the independence of judges sometimes has served to conspire against the effective autonomy of law. The Judiciary has been seen as an organ of the power structure allied with "governance" at the summit and bureaucratic manager of mass demands at the base. Thus, the independence of judges and courts has not contributed to the affirmation of citizens' rights as expected. The deficit of transparency, government interference and the corporate organization of the judiciary increase the risk of converting the Judiciary into an aristocratic instrument of the network protection organized by political and economic elites interested in expanding their privileges. On the other hand, the stabilization of the high degree of exclusion contributes to the perception of a Judiciary that adapts defensively to the demands of pressure groups. This does not imply, however, to affirm the caricature's description of a Brazilian impartiality. Such a perspective reinforces the interest in an adequately complex description of the administration of justice in constitutional discourse.

Palavras-chave: imparcialidade; independência; Keywords: impartiality; autonomy; judiciary. magistratura.

* Doutor em Direito, Estado e Constituição pela Universidade de Brasília (UnB).

Mestre em Direito pela Universidade Federal de Pernambuco (UFPE).

Membro do Grupo de Pesquisa "Política e Direito" (UnB). Procurador Federal. douglas.zaidan@gmail.com 


\section{SUMÁRIO}

\section{INTRODUÇÃO; 1 PERSONALISMO E CULTURALISMO NA NARRATIVA DA 'SINGULARIDADE' BRASILEIRA; 2 DESIGUALDADE ESTRUTURAL E IMPARCIALIDADE JUDICIAL SELETIVA NO BRASIL; CONSIDERAÇÕES FINAIS; REFERÊNCIAS}

\section{- INTRODUÇÃO}

A narrativa sociológica tradicional acerca da formação das relações sociais no Brasil exerce uma influência silenciosa e eficiente sobre o modo de funcionamento das instituições no país. A descrição de uma sociabilidade constituída a partir da herança colonial refletida no amálgama entre a mestiçagem representante da nossa identidade cultural e a estrutura hierarquizada de dominação patriarcal alcançou um alto grau de estabilização nas ciências sociais por quase todo o século XX. A cristalização desse modelo explicativo das relações entre sociedade e Estado, no entanto, tem passado por uma profunda revisão que se intensificou no final dos anos 1990, mas cujo potencial para a compreensão da atuação do Poder Judiciário permanece inexplorado.

O ideal de imparcialidade dos juízes e tribunais alcança diferentes significações como prática discursiva a partir das relações sociais subjacentes. A partir do complexo espectro em que foi construída a imagem da autoridade judiciária no Brasil, alguns fatores merecem destaque para ilustrar como uma autocompreensão distintiva de magistrados se choca com o papel institucional que Ihes foi destinado pela Constituição. Assim, aproximar-se das leituras das ciências sociais sobre como a sociedade no Brasil se vê, e de que modo essa autoobservação se articula com as práticas adotadas pelo Poder Judiciário pode dizer muito sobre o comportamento judicial e o seu efetivo compromisso de atuação imparcial.

Essa perspectiva tem como efeito alertar para o equívoco sociológico em compreender a Constituição e a atividade das instituições judiciais como frutos de uma espécie de singularidade cultural derivada da "brasilidade" autêntica, descritas por parte da tradição sociológica nacional.Para Souza ${ }^{1}$, o mito da "brasilidade" teria sua fundação na construção freyriana de Casa-grande \& senzala,engajada no esforço da afirmação ambígua de uma "identidade nacional" autocomplacente e autoindulgente, manifestada pela cordialidade, simpatia e calor humano. Em que pese tal construção ter sido fundada no culturalismo pseudocientífico colonizado que oculta o racismo, ela se tornou a principal corrente explicativa das percepções dos brasileiros sobre si.Por sua vez, a ideologia dessa singularidade nacional ganhou vigor e dimensão institucional a partir dos conceitos de "homem cordial" e "patrimonialismo", de Sérgio Buarque de Holanda². Uma apropriação que reforçou o senso com um culturalista conservador que neutraliza a autocrítica e o conflito como ações produtivas no debate político e intelectual do país.

\footnotetext{
${ }^{1}$ Souza, Jessé (2000). A Modernização Seletiva: uma reinterpretação do dilema brasileiro. Brasília: Editora da Universidade de Brasília, p. 29ss.

${ }^{2}$ Holanda, Sérgio Buarque (1996). Raízes do Brasil. São Paulo: Companhia das Letras, p. 139ss.
} 
Por outro lado, observar como algumas categorias do pensamento social foram incorporadas nos discursos que entrelaçam o direito e a política no Brasil sugere hipóteses factíveis para descrever a organização judiciária no país e compreender o exercício imparcial de sua função. A formação do pensamento constitucional no Brasil guarda complexidades próprias que se inscrevem num campo aberto de possibilidades de pesquisa e demandam descrição cuidadosa. Se desde o último quarto do século passado a produção acadêmica das ciências sociais no país parece progressivamente desvincular-se de uma autocompreensão subalterna ${ }^{3}$ ou subproduto intelectual do centro, a atenção ao tempo e espaço próprios à historicidade das ideias que ajudaram a formatar o desenho das nossas instituições judiciais precisa, de fato, ser levada a sério. E esta tarefa envolve não só o emprego de métodos adequados à análise das fontes das quais emergem aquelas ideias, mas a autoavaliação crítica sobre a possível instrumentalização da descrição do passado a serviço de ideologias.

Reconhecer a importância dessa crítica implica observar a tarefa do Judiciário sob dois prismas. O primeiro considera a semântica de sua autodescrição enquanto poder autônomo que se legitima em defesa dos direitos fundamentais e do rompimento com o passado autoritário. E o segundo toma em conta os elementos da estrutura dos interesses mobilizados no seu funcionamento e a série de limitações que eles impõem à afirmação autônoma do direito no contexto de desigualdades e exclusão no país. A articulação entre ambas perspectivas reduz o risco da sobreposição de uma visão normativa entusiasmada sobre o papel dos juízes como "guardiões" de uma constituição democrática numa sociedade ainda incivilizada, e contribui para uma descrição mais próxima da posição da magistratura e meio à constelação de interesses dos grupos de pressão organizados no país.

\section{PERSONALISMO E CULTURALISMO NA NARRATIVA DA ‘SINGULARIDADE’ BRASILEIRA}

Assim como em outras áreas das ciências sociais no Brasil, também as narrativas sobre o papel do Judiciário como poder são permeadas pela extensão de pressupostos não adequadamente refletidos. Exemplo disso é o que Jessé Souza chamou de culturalismo atávico, cujo foco demasiado no personalismo como elemento, por excelência, constitutivo da experiência brasileira, subestima o fato de que os indivíduos não optam livremente pelas características sociais e naturais que condicionam sua vida e comportamento. A crítica ao que Souza denominou de nossa "sociologia da inautenticidade", é tomada como esforço de afastar a explicação da modernização brasileira como uma dinâmica de fora para dentro, cuja seletividade reproduziria uma antinomia valorativa dos indivíduos entre europeus/burgueses

\footnotetext{
${ }^{3}$ O termo "inserção subalterna" é utilizado em Lynch, Christian(2013). "Por Que Pensamentoe Não Teoria? A imaginação político-social brasileira e o fantasma da condição periférica (1880-1970)" In: Dados-Revista de Ciências Sociais. v. 56, n. 4. Rio de Janeiro, pp. 727-767, ao analisar os fatores subjacentes ao uso distinto entre "teoria política" e "pensamento político" como referências terminológicas dirigidas à produção intelectual no capitalismo central e periférico, especificamente no Brasil, respectivamente. Também Brandão, Gildo Marçal (2005). "Linhagens do Pensamento Político Brasileiro" In: Dados Revista de Ciências Sociais. Rio de Janeiro. v. 48, n. 2, pp. 231-269, critica a tendência de agregar linhas evolutivas, famílias intelectuais e formas de pensar díspares e contextuais sob um mesmo viés explicativo de intérpretes da sociedade no Brasil. Brandão opta pela descrição das descontinuidades fragmentadas, mas também das persistentes semelhanças, entre autores clássicos da história intelectual nas ciências sociais e sua repercussão política.
} 
versus anti-europeus/interioranos ${ }^{4}$, segundo posições assumidas no processo de urbanização do país.

É a partir da narrativa que atribui os problemas brasileiros ao personalismo e ao patrimonialismo a-histórico, em contraponto à idealização hipostasiada do desenvolvimento norte-americano como exemplo da ideologia liberal clássica, que Souza problematiza a noção de modernidade nos chamados intérpretes do Brasil. Embora ele também não negue a importância das relações pessoais na solução informal de conflitos como uma espécie de "gramática dual", que separa indivíduo e pessoa no Brasil, a crítica se dirige ao déficit explicativo das categorias de iberismo pré-modernoe do personalismo, enquanto traços comuns do pensamento de Sérgio Buarque, Faoro e DaMatta. Registrando que foi na noção de jeitinho brasileiro deste último que a versão do culturalismo conservador alcançou maior repercussão e ares naturalizados na visão hegemônica do mercado e da sociedade civil organizada, inclusive membros do Judiciário ${ }^{5}$.

Focado nas particularidades da formação cultural brasileira, Roberto DaMatta reuniu traços antropológicos para justificar que entre nós, diferentemente do que ocorreu com os países que experimentaram a revolução individualista e puritana predecessora da afirmação do capitalismo, existiria uma "ética dúplice" em termos weberianos. Ou seja, de que no Brasil as noções de espaço e temporalidade seguem uma dualidade específica intermediada pelo mundo das "relações". A rua seria o espaço impessoal das leis universais e eternas. A casa, o lugar dos laços afetivos onde se misturam sangue, idade, sexo e hospitalidade. Ou seja, o local do personalismo visto como "humano e solidário". E o outro mundo sintetizaria os outros dois espaços sublimando os conflitos e contradições, sob a ideia de renúncia do 'mundo real', ao estabelecer um triângulo ritual $^{6}$, que explicaria a sociedade no Brasil.

A casa e a rua no modelo de explicação da sociabilidade brasileira de Roberto DaMatta seriam espaços delimitados que diferenciam um grupo social onde a marca seria a dos privilégios, caracterizados pelo gozo de direitos sem deveres (universo da casa), e outro onde a ausência de direitos está associada ao espaço de interação social (mundo da rua). Enquanto a casa é o espaço que representa os laços de ideia de amor, carinho e afetividade, a rua, nas palavras do autor é a "[t]erra que pertence ao 'governo' ou ao 'povo' e que está sempre repleta de fluidez e movimento. A rua é um local perigoso"7.

Opondo-se ao "provincianismo empírico" da explicação damattiana, Marcelo Neves também demonstra severas restrições às interpretações da antropologia dos problemas brasileiros baseadas na cultura nacional ou da manifestação de uma brasilidade, frequentemente invocada em sentido negativo em contraposição à modernidade europeia.

\footnotetext{
${ }^{4}$ Op. cit., p. 235.

${ }^{5} \mathrm{~A}$ título de exemplo, o senso comum refletido em texto da lecture proferida pelo ministro do STF, Luís Roberto Barroso (2017), em que um breve resumo da formação do Brasil colonial, deslocado da historicidade própria dos eventos mencionados, serve de articulação no uso da categoria damattiana de jeitinho brasileiro, para justificar uma série de afirmações sobre ética, corrupção, desigualdade e outros problemas estruturais do país, sem qualquer indicação metodológica ou apoio empírico. Para Barroso, o jeitinho é o obstáculo do "salto civilizatório de que precisamos" In: Barroso, Luís Roberto (2017). “Ética e Jeitinho Brasileiro: por que a gente é assim?". Lecture. Harvard Brazil Conference, Cambridge MA, 8 de abril.

${ }^{6}$ DaMatta, Roberto (1997). A Casa \& a Rua: espaço, cidadania, mulher e morte no Brasil. 5a ed.Rio de Janeiro: Guanabara Koogan, p. 13.

${ }^{7}$ Idem, p. 40.
} 
Ao analisar o problema da falta de autonomia do direito no Brasil, Neves ${ }^{8}$ aponta que é no déficit da afirmação dos direitos segundo procedimentos juridicamente regulados, da qual depende a deliberação política numa sociedade democrática, que o exercício da cidadania pode ser bloqueado pela ação destrutiva de particularismos políticos e econômicos.

Se para DaMatta a construção do conceito antropológico da casa e da rua são definidores dos espaços de atuação do subcidadão e do supercidadão, para Neves a rua, esfera dos sem direitos, seria também espaço sujeito ao exercício dos privilégios dos sobreintegrados. Nesse sentido, os subintegrados permaneceriam dependentes dos benefícios do sistema jurídico, sem contudo alcançá-los, o que não significaria a sua exclusão do sistema. Isso porque estariam sujeitos às prescrições impositivas própria de uma integração marginalizada, pois "embora lhes faltem as condições reais de exercer os direitos fundamentais constitucionalmente declarados, não estão liberados dos deveres e responsabilidades impostos pelo aparelho coercitivo estatal, submetendo-se radicalmente às suas estruturas punitivas" 9 .

À subintegração de amplos setores da população está associada a manutenção de privilégios dos sobreintegrados, com o expresso apoio da estrutura burocrática do Estado. Essa é a condição que garante a 'institucionalização' do bloqueio ao funcionamento adequado do direito para a conservação de privilégios incompatíveis com o regime da igualdade, com o financiamento de toda a sociedade. Ocorre que, apesar de não exaustivamente trabalhado por Neves no plano empírico, os efeitos dessa sobreintegração no acesso aos bens jurídicos constitucionalmente definidos obedecem a uma seletividade própria. Isso porque os sobrecidadãos usurpariam o discurso normativo quando em jogo os seus interesses, mas o descartariam quando a Constituição impõe limites à sua esfera de interesses políticos e econômicos. Logo, o texto constitucional não age como "horizonte do agir e vivenciar jurídicopolítico dos 'donos do poder', mas sim como uma oferta que, a depender da constelação de interesses, será usada, desusada ou abusada por eles"10.

Logo, atentar para a dimensão agonística e contingente presente na história das instituições brasileiras mostra-se mais produtivo enquanto explicação das causas do fracasso de uma cidadania nos moldes 'modernos'11. A partir dessas disputas é que se refletiram os padrões de sociabilidade e normatividade constitutivos do comportamento das nossas instituições, incluídos os juízes e tribunais. Assim, o foco das pesquisas sobre a formação aristocrática e corporativa da magistratura se associa à análise conjunta entre oportunidades políticas e práticas de luta. Uma perspectiva que não encontra espaço na nossa sociologia da

\footnotetext{
${ }^{8}$ Neves, Marcelo (1994). “Entre Sobreintegração e Subintegração: a cidadania inexistente”. In: Dados-Revista de Ciências Sociais. v. 37, n. 2, pp. 253-276.

${ }^{9}$ Idem, p. 261.

${ }^{10}$ Neves, 1994, p. 261. Em sentido semelhante, José Murilo de Carvalho descreve a estratificação social brasileira em três níveis: os cidadãos de primeira classe ou "doutores", que constituiriam $8 \%$ das famílias com renda maior que 20 salários mínimos; os de segunda classe ou "cidadãos simples", 63\% das famílias com renda entre 2 e 20 salários, e os de terceira ou "elementos" no jargão policial, formada pelos $23 \%$ das famílias com renda até 2 salários mínimos, que ignoram os próprios direitos civis e vêem na lei o aparato opressor do Estado. Cf. Carvalho, José Murilo de, 2008,Cidadania no Brasil: o longo caminho. 10 ed. Rio de Janeiro: Civilização Brasileira, p. 215.

${ }^{11}$ Tavolaro, Sergio (2009). "Para Além de uma 'Cidadania à Brasileira': uma consideração crítica da produção sociológica nacional.” In: Revista de Sociologia e Política. Curitiba: UFPR, vol. 17, n. 32, p. 114.
} 
dependência, com foco na industrialização tardia do país, ou na sociologia patriarcalpatrimonial centrada na herança ibérica.

\section{DESIGUALDADE ESTRUTURAL E IMPARCIALIDADEJUDICIALSELETIVA NO BRASIL}

Numa sociedade em que o acesso à justiça ocupa uma função determinante para a fruição dos direitos fundamentais, a exclusão do exercício desse direito à grande parte da população reforça a percepção de uma cidadania inexistente ou restrita à função simbólica do discurso constitucional ${ }^{12}$. Do estabelecimento de uma cidadania de cima para baixo ou de uma estadania $^{13}$, as relações entre a população e o Judiciário não escapam. Visto mais como órgão da estrutura de poder aliado à "governabilidade" na cúpula, e gestor burocrático de demandas de massa na base, a independência de juízes e tribunais pouco têm representado para a afirmação do sentido de liberdade e a redução da desigualdade entre os subintegrados. Nesse particular reside o principal problema de reconhecimento da confiança no Judiciário como imparcial, questão não resolvida com a recente conquista de independência do Judiciário frente ao Executivo. A análise específica dos problemas de reprodução do direito no Brasil não implica, contudo, afirmar a descrição caricatural de uma imparcialidade à brasileira.

Exemplos graves de sujeição do sistema jurídico ao personalismo dos 'donos do poder' podem ser encontrados em outras partes da sociedade mundial.A gravidade da intervenção de Berlusconi sobre procedimentos sujeitos à reserva de jurisdição na Itália é emblemática nesse sentido. A capacidade de neutralizar processos judiciais em cursos mediante a aprovação de leis ad personam mostraram como a concentração de poder político e econômico por um governante pode tornar frágil a estrutura punitiva das instituições judiciais e, pior, converter o Parlamento numa espécie de escritório de advocacia personalíssimo a serviço de negócios políticos socialmente reprováveis. Entre as medidas aprovadas em benefício de Berlusconi estavam a redução de prazos prescricionais dos crimes a ele imputados; o legítimo impedimento em frustração às citações nos processos pela alegação obrigações próprias da função de premier; a suspensão de processos durante o mandato e o aumento ou redução do tempo máximo de processos para tipos legais que o afetavam diretamente, pelas variáveis do processo breve e do processo lungo ${ }^{14}$.

Essa percepção é reforçada numa série de outros exemplos.Assim como são fartos os exemplos de manifestação do poder contra a cidadania por membros do Judiciário.É o caso da rejeição ao controle democrático pela magistratura francesa manifesto ora pelo desvio aristocrático e ora pela tentação populista, ambos alimentados pela decepção com a política ${ }^{15}$. O modo como a deificação da jurisprudência do TC da Alemanha assume um caráter

\footnotetext{
12 Neves, op. cit., p. 268.

${ }^{13}$ Carvalho, José Murilo de (1996). “O Acesso à Justiça e a Cultura Cívica Brasileira" In: Jusiça: Promessa e Realidade: o acesso à justiça em países ibero-americanos. Associação dos Magistrados Brasileiros (org.). Rio de Janeiro: Nova Fronteira, p. 290 e Carvalho, José Murilo de (2008) Cidadania no Brasil: o longo caminho. 10 ed. Rio de Janeiro: Civilização Brasileira, p. 221.

${ }^{14}$ Ibañez, Perfecto Andrés (2012). "La Independencia Judicial y los Derechos del Juez" In: Los Derechos Fundamentales de los Jueces. Arnaiz, Alejandro Saiz (dir.) Generalitat de Catalunya -Centre d’Estudis Jurídics i Formació Especializada. Madrid; Barcelona; Buenos Aires: Marcial Pons, p. 52.

${ }^{15}$ Garapon, Antonie (1996). O Guardador de Promessas. Lisboa: Instituto Piaget, pp. 53-75.
} 
paternalista em prejuízo da participação cidadã na democracia ${ }^{16}$. Ainda o relato de como o estamento dos juízes haviam transformado em fetiche a própria independência convertendoa em exigências políticas corporativistas, na Alemanha sob a Constituição de Weimar ${ }^{17}$. Também a descrição do aumento da criatividade judicial na experiência italiana entre 1948 e 1956 (período entre a promulgação da Constituição e a instalação da Corte Constitucional) e a permanência do isolamento corporativo da magistratura associada ao deficiente controle interno, tomados como propósito de sua investigação sobre responsabilização judicial ${ }^{18}$.

Vê-se que observações metodologicamente comprometidas com análises empíricas e comparativas sobre os padrões de funcionamento do sistema jurídico no plano global mostram que tais problemas não são exclusividade da modernidade periférica, atribuíveis ao jeitinho brasileiro ou sintoma de uma brasilidade mitológica e colonizada descrita em termos conservadores $^{19}$. Traços comuns desses problemas têm sido objeto da preocupação de distintos grupos de crítica em ordens locais diversas e apreciada em decisões de tribunais internacionais. Tal perspectiva reforça o interesse numa descrição adequadamente complexa da administração de justiça no discurso constitucional no Brasil.

Sob a perspectiva semântica da imparcialidade como expectativa normativa de igualdade de tratamento, a marcada desigualdade estrutural da sociedade no Brasil impõe severas restrições que se manifestam nos problemas de fechamento operativo do sistema jurídico ${ }^{20}$. Esse é um problema que adquire especial gravidade quando observado o campo discursivo dos juízes e tribunais sobre o próprio estatuto funcional e as garantias do exercício independente de suas atribuições. O déficit de transparência na atuação de ministros; as interferências governamentais na independência judicial com reflexos na imparcialidade, além da organização corporativa da magistratura ${ }^{21}$, potencializam o risco da conversão do funcionamento do Judiciário em instrumento aristocrático da proteção de redes ${ }^{22}$ de caráter estrutural excludente, organizadas por elites políticas e econômicas como trincheira na ampliação ou manutenção de seus privilégios.

Uma descrição da imparcialidade no funcionamento da administração de justiça no Brasil imprescinde dos referenciais de inclusão e exclusão presentes na reprodução das inúmeras desigualdades refletidas no acesso à justiça. A estabilização do alto grau de exclusão, refletido na autocompreensão das nossas instituições, contribui para a percepção de um Judiciário que se adapta defensivamente às assimétricas demandas dos grupos de pressão. Descrever sociologicamente o modo como essas relações de exclusão se impõem destrutivamente sobre o sentido constitucional da igualdade ocupa o fundamental espaço da

\footnotetext{
${ }^{16}$ Maus, Ingeborg (2000). “O Judiciário como Superego da Sociedade” Trad. Martônio Lima e Paulo Albuquerque. In: Novos Estudos. CEBRAP. n. 58, pp. 183-202.

${ }^{17}$ Simon, Dieter (1985). La Independencia del Juez. Madrid: Ariel.

${ }^{18}$ Cappelletti, Mauro (1989). Juízes Irresponsáveis? Trad. Carlos Alberto Álvaro de Oliveira. Porto Alegre: Sergio Antonio Fabris Editor, p. 42 eCappelletti, Mauro (1993). Juízes Legisladores? Trad. Carlos Alberto Álvaro de Oliveira. Porto Alegre: Sergio Antonio Fabris Editor, p. 7-14.

${ }^{19}$ Seja na percepção de autores nacionais DaMatta e Barroso ou estrangeiros Rosenn, Keith (1984). “Brazil's Legal Culture: The JeitoRevited" In: Florida International Law Journal. v. 1, n. 1, pp. 2-43.

${ }^{20}$ Neves, Marcelo(2011). A Constitucionalização Simbólica. 3 ed. São Paulo: Martins Fontes.

${ }^{21}$ Carvalho, Alexandre (2017). Imagens da Imparcialidade: entre o discurso constitucional e a prática judicial. SãoPaulo: Almedina.

${ }^{22}$ Luhmann, Niklas (2013). "Inclusão e Exclusão". Trad. Stefan Fornos Klein. In: Bachur, João Paulo \& Dutra, Roberto (orgs.). Dossiê Niklas Luhmann. Belo Horizonte: Editora UFMG, p. 27-36.
} 
crítica sobre os efeitos seletivos da prática judicial. Uma preocupação atual e que, segundo Florestan Fernandes, resultana consideração de que "a lei se corporifica em códigos, mas sua aplicação distorcida, com a tolerância dos que sofrem suas consequências, engendra uma cidadania e uma democracia dos privilegiados" 23 .

Essa perspectiva potencializa acrítica do déficit da imparcialidade judicial como dimensão jurídica da (des)igualdade no Brasil, enquanto exigência de tratar casos iguais de maneira igual. Se no plano normativo, o sistema jurídico impõe a adoção do comportamento judicial congruente nas esferas formal e material do acesso à justiça, no plano operativo,esse mandamento constitucional não têm produzido os resultados práticos esperados. Isso porque a sobreposição de elementos externos ao código do direito (como o poder e o dinheiro) alcança o próprio nível das expectativas sobre o funcionamento do sistema de justiças e está diante da corrupção sistêmica ${ }^{24}$, o que implica no comprometimento generalizado da autonomia operacional do direito.

Contra a corrupção sistêmica, a imparcialidade judicial precisa manifestar a capacidade de imunizar a influência de dois fatores: 1) a empatia subjetiva do juiz em relação às partes ou à causa enquanto fator determinante; e 2) o cálculo dos custos e benefícios pessoais do próprio juiz no processo de decisão. Contudo, como promover chances iguais em contextos de forte assimetria da influência das partes sobre a condução do procedimento? $E$, ainda, como descrever a imparcialidade dos magistrados quando as exigências da adequação social da decisão impliquem em conceder a uma das partes mais oportunidades?

Aqui o problema é agravado diante da percepção abrangente de que os agentes responsáveis pela aplicação do direito abandonam o seu papel para perseguir o interesse pessoal pela manipulação operativa dos programas do direito. A amplitude desta percepção atinge de modo destrutivo os níveis de confiança interpessoal, além da orientação dos litigantes em relação ao julgador -visto como agente submetido, quando não é ele mesmo o engajado, aos processos organizados de interferência e pressões externas mediados pelo poder e o dinheiro. Em tais contextos, a generalização congruente da imparcialidade enquanto meio simbólico da atuação judicial é prejudicada em duas dimensões.

A primeira delas se configura quando a representação de determinados indivíduos ou grupos de pressão (formado em parte pelos sobreintegrados) conseguem impor seus interesses particularistas na esfera deliberativa do Judiciário. Aqui, a aliança da sobreinclusão no sistema social e a desigualdade estrutural apresenta potencial efeito destrutivo de estímulo à corrupção sistêmica da qual retira proveito político e econômico. Sobre a dimensão da igualdade de oportunidades entre as partes -que marca a noção de imparcialidade judicial, esses efeitos perniciosos se manifestam. É exemplo desse efeito destrutivo da imparcialidade a contratação lobistas ou parentes de ministros para a prática de determinados atos processuais objetivando o desequilíbrio no julgamento, sem fundamento técnico ou contra ele. Mas também a realização de audiências particulares não agendadas nos gabinetes, entre julgadores e uma das partes sem a participação da parte adversa. Ainda, o patrocínio de congressos, viagens, confraternizações e outros eventos de que participam magistrados, por escritórios de advocacia ou empresas litigantes. E, por último, a extensa abertura institucional

\footnotetext{
${ }^{23}$ E completa: "A jurisprudência obedece essa trilha: conforma o Direito ao monopólio do poder das elites das classes dominantes. Malgrado sua erudição, os magistrados curvam-se à manutenção da ordem deturpada".In:Fernandes, Florestan(1993). “E o Judiciário?” In: Folha de São Paulo. Edição de 20.12.1993.

${ }^{24}$ Neves, Marcelo(2011). A Constitucionalização Simbólica. 3 ed. São Paulo: Martins Fontes, p. 146.
} 
do Poder Judiciário, em especial dos órgãos encarregados de gestão administrativa da burocracia judicial, como o CNJ, à influência corporativa das associações de juízes e demais profissionais do sistema de justiça na defesa dos interesses de seus membros.

Todos esses exemplos, que não são uma exclusividade da prática constitucional no Brasil, atuam de modo corrosivo sobre a imunização do sistema proporcionada pelos papéis institucionais adotados pelos agentes do Judiciário e, consequentemente, bloqueiam a função da confiança na atuação judicial imparcial. Este é um problema tão mais visível quanto delicado na jurisdição de tribunais como o Supremo Tribunal Federal, seja pelo mecanismo político de recrutamento dos ministros ou pela repercussão das decisões para a uniformização do direito. Nestes casos, a decisão deixa de ser vista menos como a consequência da aplicação impessoal do programa normativo a fatos do que como a sobreposição dos códigos do poder e do dinheiro cuja influência passa ser conduzida, direta ou indiretamente, à imagem pessoal do julgador.

Já a segunda pode ser observada nas legítimas aspirações pela concretização de direitos pela maior parte dos clientes do sistema de justiça(os subintegrados), que acabam projetando na imagem imparcial do juiz a expectativa cognitiva de ser ele capaz de desvincular-se do código lícito/ilícito e realizar a justiça social no caso. Sob o pano de fundo da ampla exclusão que impede a formação de um horizonte compartilhado de acesso igual a direitos e obrigações, o acesso à justiça efetiva acaba sendo visto como um privilégio concedido por um o juiz visto como uma espécie de administrador de "bens salvíficos" 25 .A assunção dessa imagem pela magistratura, por sua vez, reforça o afastamento dos juízes das características reais dos conflitos que lhe são submetidos a julgamento, contribuindo para uma visão do direito mais sacralizadodo que efetivamente respeitado.

Essa dimensão do problema se reflete na autocompreensão dos membros da magistratura que passam a atuar paternalisticamente como "super-heróis" ou "reis-juízes", com autoridade normativa suficiente para interferir na autonomia funcional de procedimentos legislativos e administrativos. A ideia subjacente de que a omissão dos agentes dos demais poderes não pode ser justificada pela formalidade constitucional da separação dos poderes se concilia então com o recurso a argumentos e decisões judiciais vagas, onde se dissolve a consistência jurídica da decisão sob equívocas premissas de atendimento ao interesse social.

Mais além dos efeitos destrutivos sobre a formação das expectativas de atuação imparcial, essa autoprojeção da magistratura enquanto agente da justiça e não do direito se sujeita à instrumentalização perniciosa no âmbito corporativo. Isso porque o deslocamento da própria imagem dos fatores contingentes próprios da distribuição desigual de bens e recursos incluem-se no ponto cego das deliberações judiciais sobre o próprio estatuto funcional. A manutenção de visões cristalizadas sobre o mérito e o esforço que julgam

\footnotetext{
${ }^{25} \mathrm{~A}$ expressão não é tomada no sentido que lhe emprega Habermas, Jürgen (2012). Direito e Democracia: entre facticidade e validade. Vol. 1. Rio de Janeiro: Tempo Brasileiro, p. 180, supondo a figura de um chefe prémoderno com poder socialmente reconhecido por uma ordem sagrada. A imagem do juiz "salvador" aqui referido se relaciona aos limites da formação consistente da imparcialidade por reflexo da exclusão massiva associada ao culto do deus ex-machina mencionado por Faoro, Raymundo (1977). Os Donos do Poder: formação do patronato político brasileiro. Vol. 2, 5a ed. Porto Alegre: Editora Globo, p. 740. Longe de suposições culturalistas, a exclusão retroalimenta as expectativas de concretização do direito na atuação pessoal de um representante burocrático, cujo poder se funda justamente no controle das contingências sociais por redes interessadas na manutenção da desigualdade excludente.
} 
constituir suas próprias carreiras repercutem diretamente na autocompreensão naturalizada que se manifesta em interpretações sobre a ampliação de benefícios salariais e outras vantagens do cargo. Desse modo, essas interpretações se mostram completamente desvinculadas de parâmetros adequados à distribuição do orçamento público no contexto de uma economia emergente, além de insustentáveis em cenários de menor desigualdade estrutural. Assim, os usos da função da imparcialidade no sistema jurídico reverberam contra a sua dimensão isonômica ao invés de promovê-la enquanto prestação jurídica relevante à inclusão.

\section{- CONSIDERAÇÕES FINAIS}

Um dos principais mitos construídos pelo discurso jurídico hegemônico no país nas três últimas décadas buscou legitimação na afirmação de que conferir ao Judiciário a responsabilidade da formulação de decisões coletivamente vinculantes era a nossa alternativa à ausência de "boa política". Este discurso deu ensejo à criação de diversos instrumentos processuais justificados no uso sofisticado da linguagem do direito comparado -muitas vezes sem correspondência com sua configuração nos ordenamentos de origem ou adequação semântica à prática constitucional no Brasil. Por outro lado, consolidava-se paulatinamente a ideia de que aqueles instrumentos funcionariam para concretizar direitos e promover a ideia de que aqueles instrumentos funcionariam para concretizar direitos e promover a cidadania. Mas, para tanto, seria preciso destinar a confiança de que eles seriam operados por agentes imparciais comprometidos com a efetividade do projeto constitucional, para o que precisavam de garantias institucionais de independência frente à política.

Essa descrição teve elementos de justificação na série de eventos autoritários na nossa história constitucional, mas também na narrativa culturalista que marca a tradição das ciências sociais no país. Sob a justificativa centrada no personalismo e no patrimonialismo como características fundamentais da reprodução social no Brasil, fazia pouco sentido alimentar as expectativas na realização da cidadania através da atuação do Executivo ou Legislativo. Enquanto órgãos de deliberação política compostos pelo critério eleitoral, estariam aqueles poderes marcados pelo folclórico jeitinho refletido na corrupção endêmica presente nos escândalos largamente noticiados pela mídia.

Já o comportamento dos órgãos judiciais permaneceu associado à visão normativa construída pela tradicional descrição de uma justiça fragilizada, formada por juízes dependentes e incapazes de se opor aos donos do poder. Uma narrativa que se transformou em mais uma mistificação que produz efeitos contrários à dimensão da igualdade enunciada no texto da Constituição. Contudo, essa mistificação, cristalizada no discurso constitucional construído no país pós-1988, já não encontra fundamento em termos empíricos. São exemplos dessa compreensão o uso das redes de contatos para a promoção interna e chegada aos tribunais, sejam os de segunda instância, superiores, com a subversão dos critérios de antiguidade e merecimento; a progressiva exposição midiática que, por um lado, procura legitimar a própria atuação, e, por outro, estimula a autopromoção individual; a forte influência corporativa na tomada de decisões sobre gestão administrativa, funcional e disciplinar, perpetuando mecanismos arcaicos de controle gerencial; a falta de transparência 
que sugere o conflito de interesses na realização de eventos para discussão de temas internos, mas patrocinados por agentes privados, não raro, diretamente interessados nos julgamentos.

Longe de serem conduzidos à explicação colonizada da singularidade cultural própria do patrimonialismo marcante da nossa 'sociabilidade',o comportamento judicial e as práticas da magistratura são, em grande medida, responsáveis pela manutenção do nosso profundo quadro de desigualdades, caracterizado pela ampla exclusão e concentração de renda, que dificilmente encontra grau semelhante em outros locais da sociedade mundial. Ou seja, ao invés de uma imparcialidade à brasileira teríamos uma imparcialidade em causa própria, caracterizada pela reserva do espaço institucional do Judiciário para a garantia de privilégios à classe dos magistrados e outros agentes do sistema de justiça. Essa usurpação da função judicial em nome do corporativismo manifesto em práticas incompatíveis com a Constituição, que violam a igualdade distributiva no Brasil, reproduziria um sentido diametralmente inverso ao da imparcialidade como tratamento isonômico, contribuindo, paradoxalmente, para o aumento do grau de exclusão social no país.

\section{REFERÊNCIAS}

BARROSO, Luís Roberto. “Ética e Jeitinho Brasileiro: por que a gente é assim?”. Lecture. Harvard Brazil Conference, Cambridge MA, 8 de abril, 2017.

BRANDÃO, Gildo Marçal. "Linhagens do Pensamento Político Brasileiro" In: Dados Revista de Ciências Sociais. Rio de Janeiro. v. 48, n. 2, pp. 231-269, 2005.

BUARQUE DE HOLANDA. Raízes do Brasil. 26 ed. São Paulo: Companhia das Letras, 1995.

CAPPELLETTI, Mauro (1989). Juízes Irresponsáveis? Trad. Carlos Alberto Álvaro de Oliveira. Porto Alegre: Sergio Antonio Fabris Editor, 1989.

. Juízes Legisladores? Trad. Carlos Alberto Álvaro de Oliveira. Porto Alegre: Sergio Antonio Fabris Editor, 1993.

CARVALHO, José Murilo de. "O Acesso à Justiça e a Cultura Cívica Brasileira" In: Jusiça: Promessa e Realidade: o acesso à justiça em países ibero-americanos. Associação dos Magistrados Brasileiros(org.). Rio de Janeiro: Nova Fronteira, 1996.

. Cidadania no Brasil: o longo caminho. 10 ed. Rio de Janeiro: Civilização Brasileira, 2008.

CARVALHO, Alexandre. Imagens da Imparcialidade: entre o discurso constitucional e a prática judicial. SãoPaulo: Almedina, 2017.

DaMATTA, Roberto. A Casa \& a Rua: espaço, cidadania, mulher e morte no Brasil. 5a ed. Rio de Janeiro: Guanabara Koogan, 1997.

FAORO, Raymundo. Os Donos do Poder: formação do patronato político brasileiro. Vols. 1 e 2. 5 ed. Porto Alegre: Editora Globo, 1977.

FERNANDES, Florestan. “E o Judiciário?” In: Folha de São Paulo. Edição de 20.12.1993.

GARAPON, Antonie. O Guardador de Promessas. Lisboa: Instituto Piaget, 1996. 
HABERMAS, Jürgen. Direito e Democracia:entre facticidade e validade. Vol. 1. Rio de Janeiro: Tempo Brasileiro, 2012.

. Jürgen. Direito e Democracia: entre facticidade e validade. Vol. 2. Rio de Janeiro:

Tempo Brasileiro, 2012.

IBAÑEZ, Perfecto Andrés. "La Independencia Judicial y los Derechos del Juez" In: Los Derechos Fundamentales de los Jueces. Arnaiz, Alejandro Saiz (dir.) Generalitat de Catalunya -Centre d'Estudis Jurídics i Formació Especializada. Madrid; Barcelona; Buenos Aires: Marcial Pons, 2012.

LUHMANN, Niklas. "Inclusão e Exclusão". Trad. Stefan Fornos Klein. In: Bachur, João Paulo \& Dutra, Roberto (orgs.). Dossiê Niklas Luhmann. Belo Horizonte: Editora UFMG, 2013.

LYNCH, Christian. "Por Que Pensamento e Não Teoria? A imaginação político-social brasileira e o fantasma da condição periférica (1880-1970)" In: Dados-Revista de Ciências Sociais. v. 56, n. 4. Rio de Janeiro, pp. 727-767, 2013.

MAUS, Ingeborg. “O Judiciário como Superego da Sociedade” Trad. Martônio Lima e Paulo Albuquerque. In: Novos Estudos. CEBRAP. n. 58, pp. 183-202, 2000.

NEVES, Marcelo. "Entre Sobreintegração e Subintegração: a cidadania inexistente". In: Dados-Revista de Ciências Sociais. v. 37, n. 2, pp. 253-276, 1994.

. A Constitucionalização Simbólica. 3 ed. São Paulo: Martins Fontes, 2011.

ROSENN, Keith. "Brazil's Legal Culture: The JeitoRevited" In: Florida International Law Journal. v. 1, n. 1, pp. 2-43, 1984.

SIMON, Dieter. La Independencia del Juez. Madrid: Ariel, 1985.

SOUZA, Jessé. AModernização Seletiva: uma reinterpretação do dilema brasileiro. Brasília: Editora da Universidade de Brasília, 2000.

. A Tolice da Inteligência Brasileira: ou como o país se deixa manipular pela elite. São Paulo: LeYa, 2015.

TAVOLARO, Sergio. "Para Além de uma 'Cidadania à Brasileira': uma consideração crítica da produção sociológica nacional." In: Revista de Sociologia e Política. Curitiba: UFPR, vol. 17, n. 32, pp. 95-120, 2009. 